The service began on February 1 on the following three frequencies, each being transmitted at a power of $10 \mathrm{~kW}$.: $0544-0615$ (hours G.M.T.), $5 \mathrm{Mc} / \mathrm{s}$. ; 0629-0700, $10 \mathrm{Mc} / \mathrm{s}$.; and 1029-1045, $60 \mathrm{kc} . / \mathrm{s}$. Each transmission is modulated in accordance with a fifteen-minute cycle, where applicable, at the following minutes past the hour: 59-00, 14-15, 29-30 and 44-45, slow morse call sign $M S F$, followed by a speech announcement; 00-05, 15-20, 30-35 and 45-50, carrier-modulated with 1,000-c./s. tone; 05-14, 20-29, 35-44 and 50-59, unmodulated carrier. It is proposed to add in due course 1-c./s. pulses during the first five minutes of each period at present unmodulated.

The transmissions on $60 \mathrm{kc} . / \mathrm{s}$. should be received throughout the United Kingdom and Western Europe and enable local standards to be calibrated with high precision; those on 5 and $10 \mathrm{Mc} / \mathrm{s}$. form part of an international programme designed to give reliable world cover on one or other of the frequencies, $2 \cdot 5$, $5,10,15,20$ and $25 \mathrm{Mc}$./s., which have been allocated to standard frequency services. The transmissions on these frequencies from the United States National Bureau of Standards station $W W V$ are not always satisfactorily received in the United Kingdom and farther east. It is hoped to learn from the experimental service now being initiated to what extent reception in the European area is improved by transmissions from the United Kingdom, and also to what extent the usefulness of both the American and the British transmissions may be impaired by mutual interference. The frequencies, which are to be maintained within two parts in one hundred million of the nominal values, will be monitored at the National Physical Laboratory, and all inquiries or comments concerning the transmissions should be addressed to the Director, National Physical Laboratory, Teddington, Middlesex. Information about reception conditions and interference with the United States transmissions will be particularly useful.

\section{Centenary of the Royal Meteorological Society}

THE centenary of the Royal Meteorological Society falls on April 3, and the following provisional programme in celebration has been arranged. A series of scientific symposia will be held at Christ Church, Oxford, in which a number of eminent foreign meteorologists will participate. The symposia at Oxford will be : March 28 (afternoon), radiation and its effect on the troposphere and lower stratosphere; March 29 (morning), physics of clouds and precipitation; (afternoon), structure of weather systems; March 30 (morning), general circulation of the atmosphere ; (afternoon), climatic change; March 31 (morning), meteorology and the community. The meeting at Oxford will terminate with a tour of the city on the afternoon of March 3I and a theatre party in the evening. On April 1 an excursion will be made to the Meteorological Office, Harrow, and at 8 p.m. a conversazione will be held in the Society's Rooms at 49 Cromwell Road, London, S.W.7. A visit to the Department of Meteorology, Imperial College of Science and Technology, will be made on the morning of April 3, and at 3 p.m. the main centenary meeting will take place in the Society's Rooms. In the evening, at 7.45 p.m., the centenary dinner will be held at the Connaught Rooms, London, W.C.1. Accommodation is available at Christ Church, Oxford, and afterwards during April 1-4 at Bedford College, London. To mark the occasion, a special meteorological exhibition is being arranged at the Science
Museum, South Kensington, London, S.W.7, and will be open for three months from March 27. Further particulars can be obtained from the Assistant Secretary of the Society.

\section{The Man of Science in Society}

Discussing the role of the man of science in society, a writer in the October 1949 issue of Endeavour supports the views of those who believe that, outside the laboratory, the personal influence of the man of science should be no more than that of any other citizen, against those who advocate a state verging on a technocracy in which men of science would have special privileges and a large measure of control. Despite his training in scientific method and his ability to store technical information and to interpret it, the man of science is but a link in a long chain and is no more indispensable than other links which support him. There are administrative and economic factors of which the man of science usually knows very little. The majority of men of science-and the informed lay public-feel that science has only limited use in the solution of problems largely influenced by emotional and other imponderable factors. Human problems can only be solved by the accumulated wisdom of responsible laymen who interpret such problems in the light of long and varied experience in human relations and which, until we know vastly more than we do to-day about the working of the human mind, can only be described as intuitive. To make the best use of science there is need for numbers of men of a type which to-day is scarce but not unknown-those who have had a thorough scientific education but have also had considerable experience in practical affairs.

\section{Exchange of Diagrams and Data between Radia- tion Therapy Centres}

The scheme, organised by the Hospital Physicists' Association, for the exchange of useful diagrams and data between radiotherapy centres is discussed in the British Journal of Radiology (February, 23, 139; 1950). Most centres accumulate isodose and other charts, nomograms, machine drawings and tabulated data, which would often be useful to many other centres, and diagrams in the literature are generally too small to be of practical use, whereas large copies of the originals might be useful. Therefore, catalogues have been issued by the Hospital Physicists' Association, describing all the material available of which copies can be supplied by the honorary secretary of the scheme. Catalogue $A$, issued in December 1944, contained 213 items, and Catalogue $B$, of June 1946, more than two hundred. By the end of 1949 the inquiries about the scheme and requests for catalogues showed no signs of abatement, and about four hundred copies of the first two catalogues had been distributed to all parts of the world. The total number of diagrams, etc., now distributed exceeds 2,500-45 per cent of which have gone outside Great Britain. Within a single recent period of twelve months, nearly nine hundred items were dispatched. Thescheme has been run so that it is justself-supporting financially, and costs have been reduced to an average of $3 s$. $2 d$. for a negative copy of a diagram and about $2 s$. for a paper copy of an X-ray isodose chart. The Hospital Physicists' Association will demonstrate the working of the scheme at a stand in the Scientific Exhibition Section of the forthcoming Sixth International Congress of Radiology which will be held in London in July. Catalogue $C$, with 270 items classified 